\title{
Simultaneous determination of phenylureas and triazines in water, by capillary gas chromatography with ion trap detection and large volume injection
}

\author{
C. Charrêteur ${ }^{1}$, R. Colin ${ }^{1}$, D. Morin ${ }^{2}$ and J.J. Péron ${ }^{2}$ \\ ${ }^{1}$ Laboratoire d'Hygiène Publique et Industrielle, Université de Bretagne Sud, \\ Centre de Génie Industriel, Guidel-plages, 56520 Guidel, France \\ ${ }^{2}$ Laboratoire de Chimie Analytique Appliquée, Université de Bretagne Sud, \\ Centre de Génie Industriel, Guidel-plages, 56520 Guidel, France
}

\begin{abstract}
A GC method is described for the simultaneous determination of triazines and phenylureas in aqueous samples by large volume injection with a Programmable Temperature Vaporisator injector (PTV) and ion trap detection (ITD). The analytical column (DB 5MS, $30 \mathrm{~m}, 0.25 \mathrm{~mm}, 0.25 \mu \mathrm{m}$ ) is connected to a pre-column (DB 5MS, $5 \mathrm{~m}, 0.25 \mathrm{~mm}, 0.25 \mu \mathrm{m}$ ) via a cross piece valve (MCS) to prevent residual solvant vapour from polluting the analytical column. The 8 pesticides (4 triazines and 4 ureas) are determined by this method, the linearity is improved using 2 Fisher test. The detection and the quantification limits are also determined for each compounds and are less than $0.10 \mu \mathrm{g} / \mathrm{L}$ which is the limit fixed by the ECC reglementation on drinking water.
\end{abstract}

\section{Introduction}

Phenylureas and triazines are extensively used in agriculture as selective herbicides, mainly for precrop emergence and for weed control by inhibiting photosynthesis [1]. Residues of these compounds can be found in soils and surface, ground and sometimes drinking waters. It can be interesting to have a common analytical method for these two families of pesticides [2].

Multiresidus methods using High Performance Liquid Chromatography (HPLC), including the determination of these compounds have been today largely tested, one knows their interests and limits [3].

In Gas Chromatography (GC), multiresidues methods have been less developed, most likely because of the multiplicity of analytical conditions as regards separation as well as detection. Recently, multiresidues methods of pesticides analyses have been described by Gas Chromatography coupled to mass spectrometry detectors (GC/MSD) [4-8] or more classical detectors like electron capture (ECD) [9], nitrogen-phosphorus (NPD) and thermoionic (TSD) detectors [10-12]. But none of these studies shows simultaneous analysis of phenylureas and triazines, with the exception of Benfenati's [4] which analyses a phenylurea (linuron) together with several other compounds. It's true that the derivatisation step of ureas makes the matter more difficult [13].

Usually, these two families are determined separately by $\mathrm{GC}$, but their extraction from water is generally performed by dichloromethane $\left(\mathrm{CH}_{2} \mathrm{Cl}_{2}\right)$, each organic extract is then concentrated, derivatised for ureas, before injection in the chromatograph. So as to analyse simultaneously these pesticides, the injection of one single extract can be considered provided the derivation of phenylureas does not lead to the loss of triazines.

In a previous study [14] a method to analyse ureas by derivatisation with Hepta Fluoro Butyric Acid (HBFA) on apolar column was used, triazines are analysed on a polar column, resulting in an excellent separation of 9 triazines. Unfortunetly derivatised ureas are not eluted from this type of column; we will therefore try to analyse a mixture of triazines and ureas on apolar column from which both families are eluted.

The TSD detector is well adapted to the determination of triazines but for simultaneous analyses of ureas and triazines we have chosen the use of an ion trap detector (ITD) since preliminary attemps realised with TSD detector were not encouraging. We will briefly describe these attempts, then we will show that it is interesting to couple ITD with large volume injection (LVI), a technique we have already validated for triazines $[15,16]$. For a review of methods for the analysis by large volume injection, the reader is referred to two recent papers and the literature cited therein $[17,18]$.

We have limited our study to 8 molecules commonly used and we have tried to analyse them in a single injection by GC. These are 4 phenylureas (diuron, isoproturon, chlortoluron and linuron), 3 triazines (atrazine, simazine and terbutylazine) and 1 degradation compound of atrazine (desethylatrazine).

\section{Materials and methods}

The 8 substances investigated purchased from CIL-Cluzeau are of certified purity (Ste Foix la Grande, Bordeaux, France). Stock solution of these herbicides are prepared in acetonitrile $(1.00 \mathrm{~g} / \mathrm{L}$ except for simazine $0.25 \mathrm{~g} / \mathrm{L})$. For dilution, extraction and derivatisation procedure 
dichloromethane is used. All solvents for Pesticides analysis are from Carlo Erba (Rueil Malmaison, France). HBFA and phosphate buffer $\mathrm{pH} 8,0\left(50 \mathrm{~mL} \mathrm{Na} \mathrm{HPO}_{4} 0.05 \mathrm{M}\right.$ and $4 \mathrm{~mL}$ $\left.\mathrm{NaH}_{2} \mathrm{PO}_{4}, 2 \mathrm{H}_{2} \mathrm{O} 0.05 \mathrm{M}\right)$ are supplied by Sigma Aldrich Chimie (St Quentin Fallavier, France). Standards are prepared in deionised water and treated in the same way as samples.

\section{Instrumentation}

Capillary GG is carried out on a Varian 3400cx fitted with a $30 \mathrm{~m}(0.25 \mathrm{~mm}$ I.D) fused-silica column coated with a $0.25 \mu \mathrm{m}$ film of DB-5MS stationary phase (J.W. Scientific, Folsom, CA, USA).

Mass spectrometric measurements are made with an ion trap detector Saturn IV (Varian, Sunnyvale, CA, USA) operating in electronic impact mode (EI) at $70 \mathrm{eV}$ and tuned by the autoset up program. The carrier gas is Helium N60 (Alphagaz Paris, France).

The large volume injector is a CIS-3 PTV injector from Gerstel (Mulheim a/d Ruhr, Germany) (Fig. 1) equipped with a special desactivated baffled liner. This system involves the slow introduction of the sample into the injection port liner. The solvent is volatilized while the analytes of interest are condensed on the baffled liner. The special pneumatics of the CIS-3 optimizes this procedure by providing a solvent vent - stop flow (SV-SF) mode, where the solvent is volatilized to atmosphere through a split vent, and the column head pressure is reduced to ambient pressure. The organic sample is injected into the CIS at an optimized speed (see operating conditions) and transferred onto a retention gap in splitless mode by a rapid heating of the CIS. $2 \mathrm{~m}$ of desactivated column $0.32 \mathrm{~mm}$ I.D is used as retention gap and moreover there is $5 \mathrm{~m}$ of fused-silica coated with DB-5MS (0.25 mm I.D) coupled with the retention gap using a glass press-fit. This piece of column permits to separate the solvent residues from the pesticides after injection (Fig. 2). A multi column switching (MCS) from Gerstel makes the connection between the pre-column and the analytical column. This system allows to blow away from the analytical column the residues of dichloromethane, which have not been eliminated during the injection step. The operating conditions for the oven, the CIS injector and the MCS connector are as follows:

- Oven temperature: initially $50{ }^{\circ} \mathrm{C}$ for $1 \mathrm{~min}$, increased at rate $20^{\circ} \mathrm{C} / \mathrm{min}$ to $160{ }^{\circ} \mathrm{C}$, held for $16 \mathrm{~min}$ isothermal, increased at rate $5^{\circ} \mathrm{C} / \mathrm{min}$ to $250^{\circ} \mathrm{C}$, final hold for 10 min isothermal. GC/ITD interface $260{ }^{\circ} \mathrm{C}$.

- Detector parameters: Manifold $220^{\circ} \mathrm{C}$, filament $30 \mu \mathrm{A}$, solvent delay $5 \mathrm{~min}$, acquisition range $60-50 \mathrm{~m} / \mathrm{z}$, background mass $45 \mathrm{~m} / \mathrm{z}$, threshold 1 .

- CIS-3 temperatures: initially $35^{\circ} \mathrm{C}$ for $0.7 \mathrm{~min}$, increased at rate $12{ }^{\circ} \mathrm{C} / \mathrm{s}$ to $250{ }^{\circ} \mathrm{C}$, held for $2.5 \mathrm{~min}$ isothermal, increased at rate $12{ }^{\circ} \mathrm{C} / \mathrm{s}$ to $300{ }^{\circ} \mathrm{C}$, final hold $2.5 \mathrm{~min}$ isothermal.

- CIS pneumatics: SV-SF mode, purge time $0.5 \mathrm{~min}$, splitless time $1.5 \mathrm{~min}$, column head pressure $1 \mathrm{bar}$, split ratio 110. Injection speed $90 \mu \mathrm{L} / \mathrm{min}$.

- MCS pneumatics: pressure 0.6 bar, flow $15 \mathrm{~mL} / \mathrm{min}$, initially cut on to cut off at $3 \mathrm{~min}$.

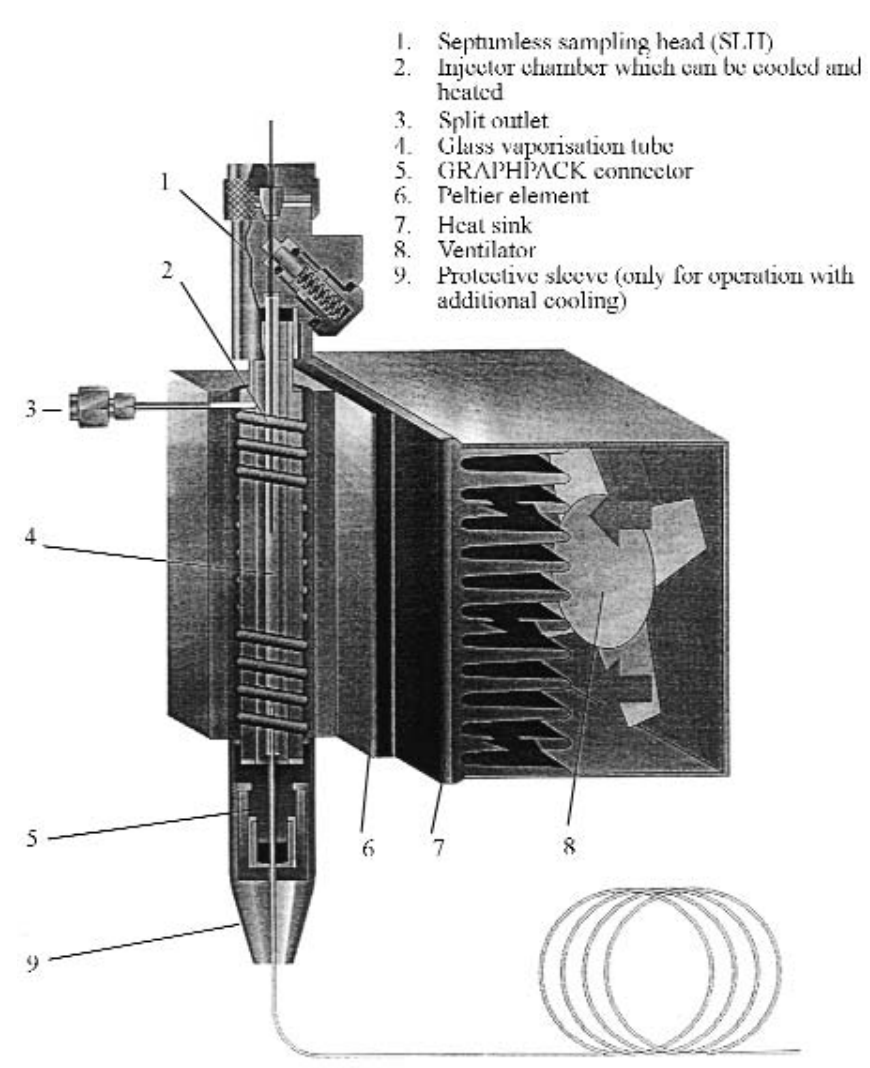

Fig. 1. Large Volume Injector CIS-3 from GERSTEL.

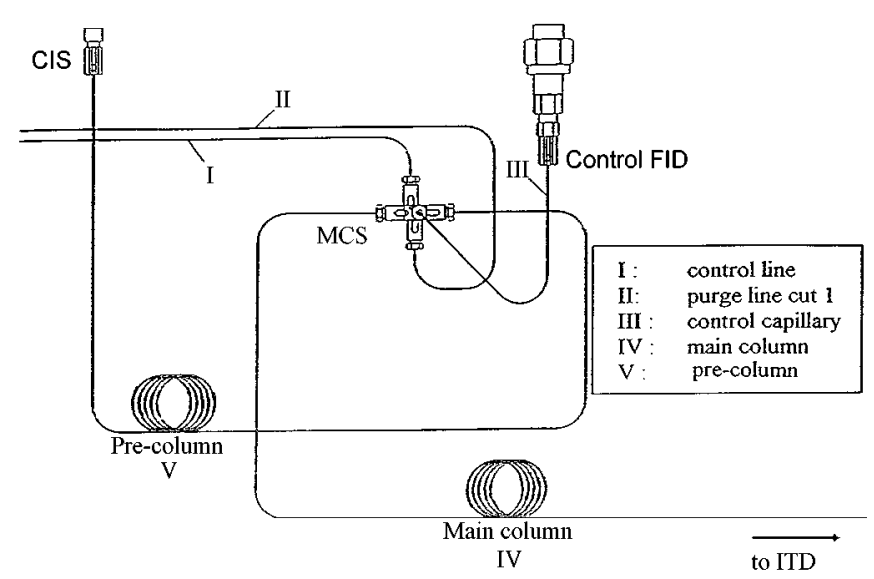

Fig. 2. Analytical system with the CIS injector, the MCS cross piece, the main and the pre column.

Calibration graphs are constructed for each compounds by using the internal standard method with triadimefon as internal standard $(m / z=208)$ at $250 \mu \mathrm{g} / \mathrm{L}$. The calibration range is from $25 \mu \mathrm{g} / \mathrm{L}$ to $200 \mu \mathrm{g} / \mathrm{L}$ which corresponds in water sample from $0.05 \mu \mathrm{g} / \mathrm{L}$ to $0.40 \mu \mathrm{g} / \mathrm{L}$. The recovery of extraction for both families of pesticides has been described in a previous work and for all compounds it is equal or better than $90 \%$ [14].

\section{Sample extraction and derivatisation}

$500 \mathrm{~mL}$ of water sample is extracted under neutral conditions ( $\mathrm{pH} \mathrm{7-8)}$ with 3 times $50 \mathrm{~mL}$ of dichloromethane. The organic layer is dried 2 hours at $-20^{\circ} \mathrm{C}$, filtered on conditioned glass wool ( 1 night at $200^{\circ} \mathrm{C}$ ) and evaporated to 


\section{Original articles}

dryness under a gentle stream of nitrogen. The dry residue is dissolved in $1 \mathrm{~mL}$ of dichloromethane. To this solution $20 \mu \mathrm{L}$ of HBFA is added, the mixture is shaken for $0.5 \mathrm{~min}$ and derivatised during 1 hour at $37^{\circ} \mathrm{C}$. The vial containing phenylurea heptafluorobutyrates and triazines is purified with the addition of $1 \mathrm{~mL}$ of phosphate buffer to eliminate the excess of HBFA. The vial is then shaken for $0.50 \mathrm{~min}$ and the organic layer is analysed by GC/ITD.

\section{Statistical validation of the analysis method}

We have first evaluated the linearity model of the method on each compound by using a Fisher test (Anova 1), it is dedicated to explain the variations of the detector response (integration areas) and the concentrations. The test compares the variance explained by the regression to the residual variance not explained by the regression. If the first one is superior to the second one, the linear model explains significantly the variation of measured areas with concentration. The evaluation of the correlation coefficient $R^{2}$ gives the percentage of the measured areas explained by the regression. But the numerical value of $R^{2}$ does not necessarily indicate a linear calibration function. In fact, a second Fisher test must be applied to well designed calibration experiments and can show significant lack of feet to a linear model (Anova 2). All this methodology has been described in literature [19]. We calculate the limits of detection and quantification in regard of the standard deviation of the origin of the calibration curves.

\section{Numerical applications}

The experimental model was $n$ standard (5) and $p$ measurements (5): for $C_{1}$ (concentration of standard 1) $R_{11}$ to $R_{1 p}$ (where $R$ is the ratio of standard area on the internal standard area) are measured.

$$
\begin{array}{lll}
C_{1} & R_{11}-R_{1 p} \\
C_{2} & R_{21} \longrightarrow R_{2 p} \\
C_{n} & R_{n 1} & R_{n p}
\end{array}
$$

The calibration function is estimated by linear regression from the data $R_{i j}=a+b C_{i}$. The values of $a$ and $b$ are obtained by minimizing $\sum\left(R_{i j}-\hat{R}_{i}\right)^{2}$ where $\hat{R}_{i}=a+b C_{i}$. The values $r_{i j}=\left(R_{i j}-\hat{R}_{i}\right)$, i.e. the vertical distances between the experimental points and the fitted line, are called "residuals".

The sum $Q_{\text {tot }}$ of standard deviation squares between the observations $R_{i j}$ and the average $R_{\mathrm{M}}$ of $R_{i j}$ can be broken in 3 terms: $Q_{\mathrm{tot}}=Q_{\mathrm{pe}}+Q_{\mathrm{lof}}+Q_{\mathrm{reg}}$. The sum of squares due to pure error has $n(p-1)$ degrees of freedom, is given by: $Q_{\mathrm{pe}}=\sum_{i j}\left(R_{i j}-\bar{R}_{i}\right)^{2}$, where $R_{i}=\sum_{i j} \bar{R}_{i j / p}$ (little average for 1 concentration level). The sum of squares due to lack of fit, obtained by: $Q_{\text {lof }}=\sum_{i j}\left(\bar{R}_{i}-\hat{R}_{i}\right)^{2}$ and has $n-2$ degrees of freedom. The sum of squares $Q_{\text {reg }}$ given by: $Q_{\text {reg }}=\sum_{i j}\left(\hat{R}_{i}-Y_{\mathrm{M}}\right)^{2}$ where $Y_{\mathrm{M}}=\sum_{i j} R_{i j / n p} \quad$ (big average). To test the lack of fit the mean squares are calculated

$$
V_{\mathrm{pe}}=Q_{\mathrm{pe}} / n(p-1) \text { and } V_{\text {lof }}=Q_{\text {lof }} /(n-2)
$$

$$
f_{\text {exp }}=V_{\text {lof }} / V_{\text {pe }} \text {. }
$$

If, by reference to a table of critical values $\left(f_{\text {theo }}=f_{n-2, n(p-1)}\right)$, $f_{\text {exp }}$ is found to be significantly greater than unity, the idea of goodness of fit can be rejected. Lack of fit can arise from causes other than non-linearity, so inspection of the residual plot is essential.

\section{Results and discussions}

\section{Theoretical}

Selective solvent elimination is an attractive way to introduce large amounts of diluted samples into a capillary column. Independent of all the methods used for this purpose (PTV, On-column, LC/GC...), the speed of sample introduction and the rate of solvent elimination have to be matched [20-22]. In a recent paper [23], we have described all these steps for the analysis of triazines in water using a PTV injector ( $800 \mu \mathrm{L}$ injected). We have used in this paper the same conditions for both families of pesticides.

\section{Preliminary attemps by LVI/GC/TSD}

The first aim of this study is to test the analytical performances of the LVI/GC/ITD system for the simultaneous analysis of phenylureas and triazines. These preliminary attemps using a thermoionic detector show efficiently the difficulties of this simultaneous analyse. The TSD is well performed to the analyse of triazines in water after a liquid/liquid extraction step and the injection of $1 \mu \mathrm{L}$ of the organic layer [10-12].

But the minimum detectable amount of phenylureas by a TSD detector is not sufficient to reach the detection limits imposed by the EEC regulations [24], which leads us to use straight away a large volume injector to compensate the lack of sensitivity.

For triazines, we inject up to $800 \mu \mathrm{L}$ of the organic extract without loss of solutes. Using the same procedure as in our previous paper we also achieve the injection of $800 \mu \mathrm{L}$ for the phenylureas without loss of solutes. We also check that the derivatisation of ureas will not lead to the loss of triazines. The chromatogram (Fig. 3) is obtained with the injection of $800 \mu \mathrm{L}$ of solution containing the 4 ureas at $10 \mu \mathrm{g} / \mathrm{L}$ levels and the 4 triazines at $0.15 \mu \mathrm{g} / \mathrm{L}$. It's clear that the total separation of all these compounds on an apolar column is not likely to be obtained. 4 compounds are eluted in less than 30 seconds in spite of a slow rise in temperature programming. As mentioned, all ureas are retained on polar column which allows excellent separation of triazines. So we test a phase of intermediate polarity (DB-35MS 35\% phenyl). This time, ureas are eluted with the exception of diuron, which is often present in surface waters; so there is little choice but the use of an apolar column.

In addition, the simultaneous quantification of both families by GC/TSD is a real problem because of the difference in sensitivity between these two families of pesticides using the TSD detection. Generally in most samples tested, it is possible to analyse ureas by GC/TSD with large volume injection $(800 \mu \mathrm{L})$ at trace level $(0.1 \mu \mathrm{g} / \mathrm{L})$, but for the 4 triazines the areas of integration are out of the calibration range, a dilution is then necessary and also an another injection. In this case, we cannot call it simultaneous determination. 


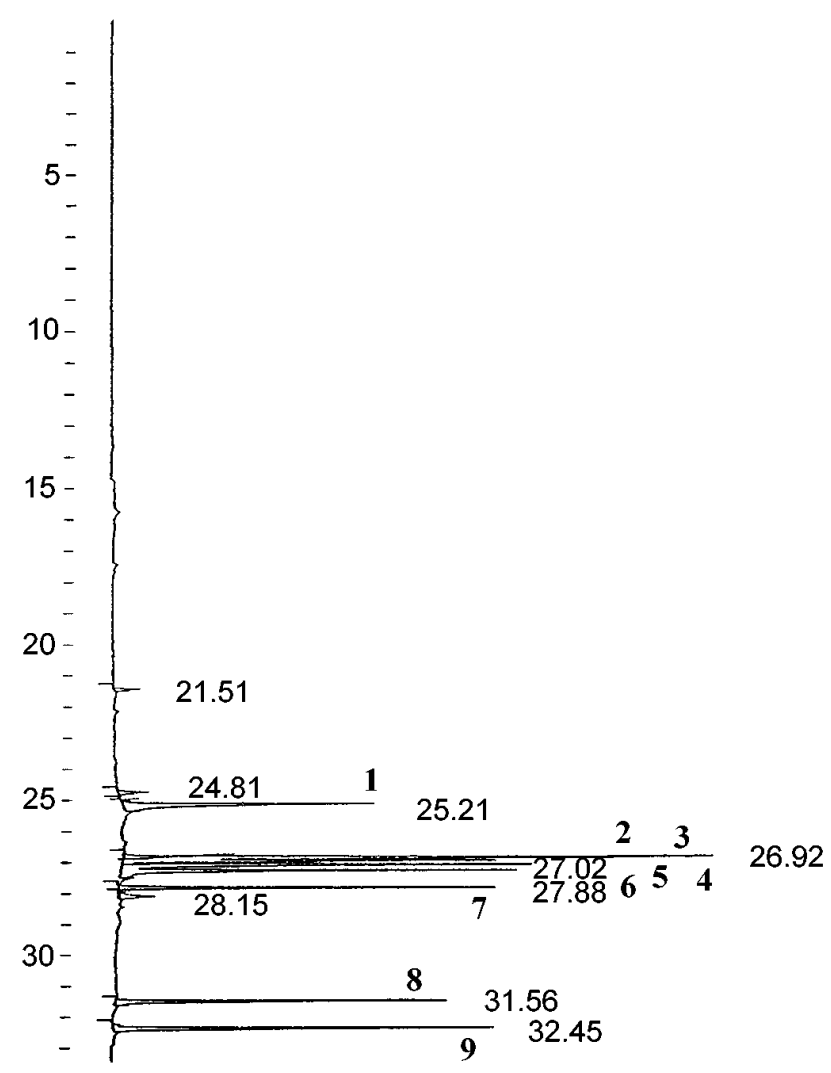

Fig. 3. Chromatogram of the $9^{\text {th }}$ compounds analysed by LVI/GC/TSD, $V=800 \mu \mathrm{L}$ in SV-SF mode; baffled liner; split ratio $1 / 100$. Analytical conditions are described in materials and methods. 1: desethylatrazine; 2: isoproturon; 3: chlorotoluron; 4: simazine; 5: atrazine; 6: terbutylazine; 7: diuron; 8: linuron; 9: internal standard.

In spite of these difficulties we have achieved linear calibration curves for each of these products. But we believe that the interest of these method is disputable.The inequal sensitivity of the TSD detection as regards these two families together with a poor resolution make the exploitation of chromatograms difficult.

\section{Simultaneous analysis of phenylureas and triazines by LVI/GC/ITD}

The latter attemps have allowed us to test the reliability of large volume injection and have shown the difficulties of simultaneous determination of triazines and ureas. The ion trap detection can permit to solve quantification problem due to the lack of resolution by the chromatogram reconstitution option of the software (reconstitution of chromatogram on 1 characteristic ion of a target compound). When 2 compounds are co-eluted, it is interesting to redraw the chromatogram on the characteristic ions of both molecules, this provides the resolution of molecules if the selected ions are not common. The second aim of the paper is to evaluate this possibility given by the ITD to succeed in the simultaneous analysis of phenylureas and triazines.

We have already validated the methodology for the analysis of ureas in water by GC/ITD after extraction and derivatisation with HBFA in dichloromethane and with a classical injection (1 $\mu \mathrm{L}$ with SPI) [14]. The calibration range is from $25 \mu \mathrm{g} / \mathrm{L}$ to $200 \mu \mathrm{g} / \mathrm{L}$ in the organic extract which permits to obtain a quantification limit equal to $0.05 \mu \mathrm{g} / \mathrm{L}$ in water. The main drawback of this method comes from the fact that the quantification is realised on major ions but not on characteristics ones. For most ureas, these ions are $61 \mathrm{~m} / \mathrm{z}$ and $72 \mathrm{~m} / \mathrm{z}$, where the bottom noise of the ITD is important. Moreover, ion $72 \mathrm{~m} / \mathrm{z}$ is common to chlortoluron and isoproturon, 2 ureas which are co-eluted on apolar column under conditions described below. It's therefore desirable to quantify on more representative ions, as the molecular ones. For isoproturon, chlortoluron, linuron and diuron, it's possible to use respectively the $402 \mathrm{~m} / \mathrm{z}$, $408 \mathrm{~m} / z, 248 \mathrm{~m} / \mathrm{z}$ and $427 \mathrm{~m} / \mathrm{z}$ ions when the organic extract is concentrated enough. Unfortunately, in the range of detection limits these ions are not present or present in small amount, which increases the uncertainty for the determination of compounds and also their quantification.

We have attempted to obtain these characteristic ions in sufficient amount by coupling the GC/ITD with the large volume injector. Table 1 shows the response of ITD (in surface) on these molecular ions for $100 \mu \mathrm{L}$ and $500 \mu \mathrm{L}$ injected and for a concentration equal to $25 \mu \mathrm{g} / \mathrm{L}$ for the $4^{\text {th }}$ ureas.

Table I. Comparison between the ITD response with a classical injection $(1 \mu \mathrm{L})$ for ureas on their molecular ions and the LVI/GC/ITD methods for 100 and $500 \mu \mathrm{L}$ injected. The response are given in surface of pic after reconstitution of chromatograms and the concentration is $25 \mu \mathrm{g} / \mathrm{L}$ in the organic extract.

\begin{tabular}{lcccc}
\hline & & GC/ITD & \multicolumn{2}{c}{ LVI/GC/ITD } \\
compounds & $m / z$ & $1 \mu L$ & $100 \mu L$ & $500 \mu L$ \\
& & & & \\
\hline isoproturon & 402 & 678 & 21432 & 45671 \\
chlortoluron & 408 & 421 & 11202 & 23453 \\
diuron & 427 & 124 & 3304 & 7600 \\
linuron & 248 & 478 & 8944 & 17032 \\
\hline
\end{tabular}

Table I clearly shows that $100 \mu \mathrm{L}$ are sufficient to obtain a good sensitivity; furthermore, we notice that for $500 \mu \mathrm{L}$ injected a degradation of the ITD response occurs and determines that this degradation is due to the residus of HBFA which have not been eliminated during the step of purification with the phosphate buffer. This reagent is present on the analytical column and can cause perturbations, which give a drift of the chromatogram trace and a lack of resolution for many peaks [25].

The chromatogram obtained after a $100 \mu \mathrm{L}$ injection of a standard solution $(200 \mu \mathrm{g} / \mathrm{L})$ of the 8 pesticides in dichloromethane is shown in figure 4 . Three compounds are eluted in 13 seconds (isoproturon, chlortoluron and simazine) and the separation between atrazine and simazine is also poor. For these compounds the interest of the reconstructed chromatograms appears clearly in figure 5. The quantification for both isoproturon and chlortoluron on respectively ions 402 and $408 \mathrm{~m} / \mathrm{z}$ is now possible and we also obtain some really characteristic mass spectra for these ureas (Fig. 6) compared to their mass spectra in a classical GC/ITD analysis [14]. Atrazine and simazine are quantified using respectivelly ion $215 \mathrm{~m} / \mathrm{z}$ and $201 \mathrm{~m} / \mathrm{z}$ [16]. The other compounds can be analysed using the total chromatogram as well the reconstituted one. For all compounds we obtain characteristic spectra identical to those obtained for pure compounds by ITD or 


\section{Original articles}

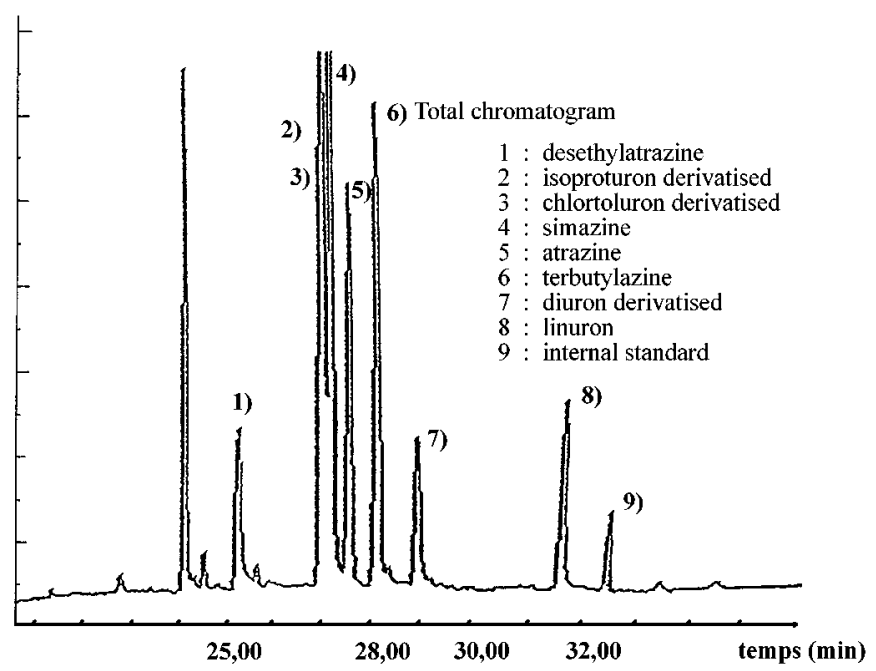

Fig. 4. Total ion chromatogram of the $9^{\text {th }}$ compounds analysed by LVI/GC/ITD. $V=100 \mu \mathrm{L}$ in SV-SF mode; baffled liner; split ration $1 / 100$. Analytical conditions are described in materials and methods.

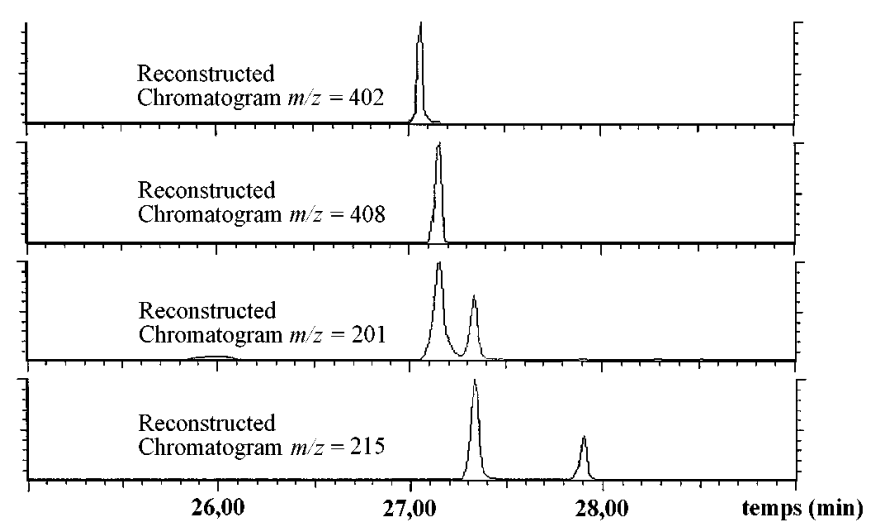

Fig. 5. Reconstructed chromatograms on specific ions for all compounds analysed by LVI/GC/ITD. $V=100 \mu \mathrm{L}$ in SV-SF mode; baffled liner; split ration 1/100. Analytical conditions are described in materials and methods.

quadrupole MSD as described by Karg [26]; this makes the technique very sensitive at low concentrations.

\section{Validation of the LVI/GC/ITD method for the simultaneous determination of phenylureas and triazines}

The linearity of the method response was tested in the $25-200 \mu \mathrm{g} / \mathrm{L}$ range for $100 \mu \mathrm{L}$ injections for all $8 \mathrm{com}$ pounds tested ( $n=5$ injections). The results are shown in table II. For all compounds the regression coefficients, $R^{2}$, were equal to or better than 0.97 , excepted for linuron and simazine (0.92). The Anova 1 test (Tab. III) is positive at the $95 \%$ level for all compounds, which means that $97 \%$ of the observations (integration areas) are explained by the linear regression, except for linuron and simazine $(92 \%)$. The ANOVA 2 test has not displayed a lack of fit of the method (Tab. III), because the lack of feet variance was not superior to the pure error variance.

The detection and quantification limits were calculated with the standard deviation of the origin $Y$-axis [27]. For all compounds the detection limits are less than $0.10 \mu \mathrm{g} / \mathrm{L}$ which is the limit of potability for drinking water in the
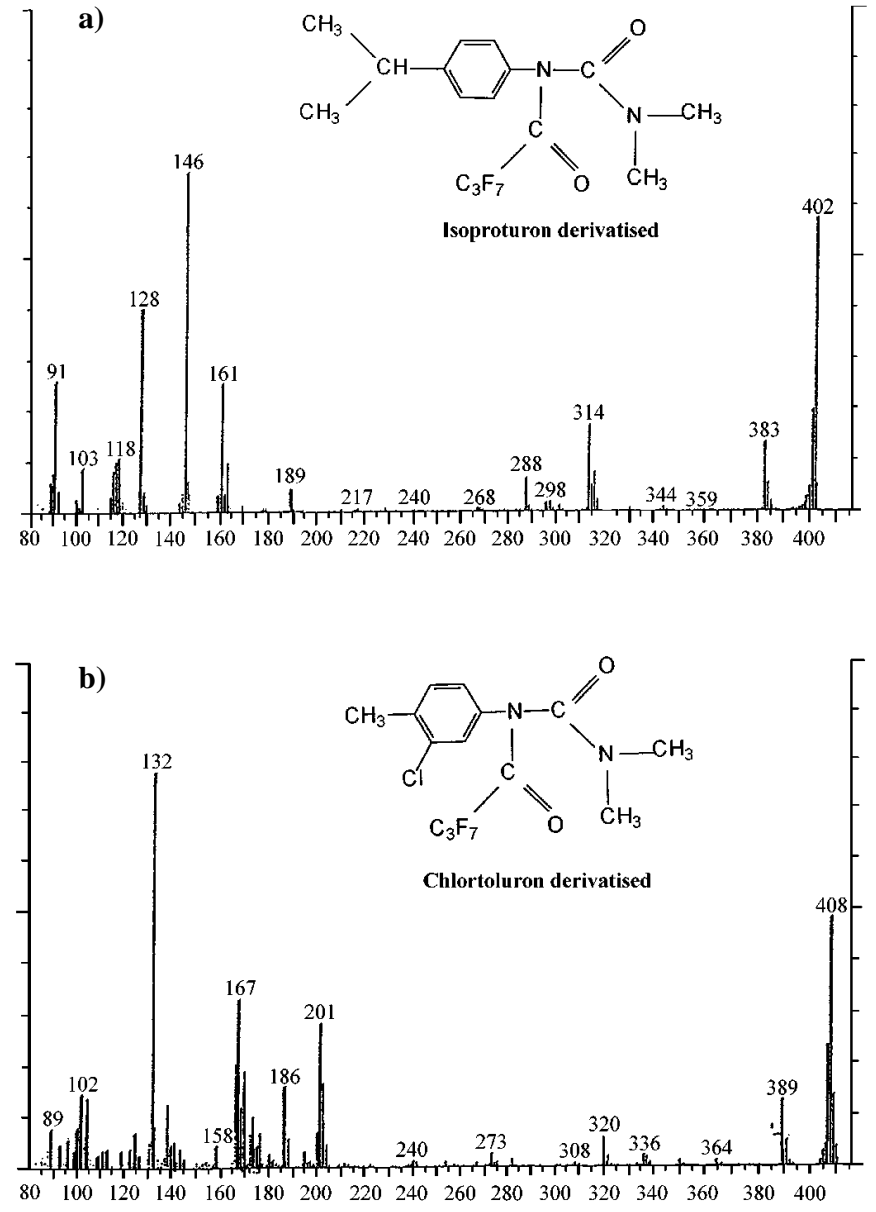

Fig. 6. Mass spectra of two ureas obtained by ILV/GC/ITD method, $[C]=200 \mu \mathrm{g} / \mathrm{L}$.

European Community. Some quantification limits are higher than this limit value, but it is probably due to the fact that the 5 injections were not realised in real repeatability conditions: because of the presence of HBFA in organic extracts and because of the $100 \mu \mathrm{L}$ injection, we were obliged to cut the retention gap after 15 injections to preserve good resolution of the chromatogram peaks, these 5 injections were also made on several days. As mentioned previously the quantification of pesticides is now made on the characteristic ions of each one which provides to the method a better specificity than the classical one which uses the $1 \mu \mathrm{L}$ injection and the quantification on 72 and $61 \mathrm{~m} / \mathrm{z}$ ions for ureas.

If we make the quantification on less characteristic ions such as $61 \mathrm{~m} / \mathrm{z}$ for linuron or $72 \mathrm{~m} / \mathrm{z}$ for chlortoluron and isoproturon, obviously the detection limits will be largely decreased in comparison to the classical method described in previous work. But this method using large volume injection which permits the identification and the quantification of molecules with their specific ions, allows us to assert, without ambiguity, the presence of both ureas and triazines in water at trace levels. This is done in one injection and the determination of these two families of compounds is a real simultaneous determination by GC. 
Table II. Parameters of the calibration curves $Y=a+b X$, correlation coefficient, standard deviation for the origin $Y$-axis, detection and quantification limits and relative standard deviation for the quantification limit of the 8 compounds using the LVI/GC/ITD method. $n=5$ injections for each point of the calibration range, $100 \mu \mathrm{L}$ injected.

\begin{tabular}{|c|c|c|c|c|c|c|}
\hline Compounds & $\begin{array}{c}\text { equation } \\
Y=a+b X(1)\end{array}$ & $\begin{array}{l}R^{2} \\
(2)\end{array}$ & $\begin{array}{l}S D a \\
(3)\end{array}$ & $\begin{array}{c}L O D \mu g / L \\
\quad(4)\end{array}$ & $\begin{array}{c}L O Q \mu g / L \\
(5)\end{array}$ & $\begin{array}{l}\% \operatorname{RSD}(6) \\
\text { for } L O Q\end{array}$ \\
\hline \multirow[t]{2}{*}{ diuron } & $a=-0.0054$ & 0.97 & 0.0052 & 0.04 & 0.09 & 15 \\
\hline & $b=0.0011$ & & & & & \\
\hline \multirow[t]{2}{*}{ chlortoluron } & $a=-0.0052$ & 0.97 & 0.012 & 0.04 & 0.09 & 10 \\
\hline & $b=0.0028$ & & & & & \\
\hline \multirow[t]{2}{*}{ simazine } & $a=-0.0240$ & 0.92 & 0.039 & 0.07 & 0.15 & 9 \\
\hline & $b=0.0052$ & & & & & \\
\hline \multirow[t]{2}{*}{ atrazine } & $a=-0.020$ & 0.98 & 0.026 & 0.03 & 0.07 & 7 \\
\hline & $b=0.0072$ & & & & & \\
\hline \multirow[t]{2}{*}{ isoproturon } & $a=-0.0079$ & 0.99 & 0.020 & 0.02 & 0.05 & 11 \\
\hline & $b=0.0077$ & & & & & \\
\hline \multirow[t]{2}{*}{ terbutylazine } & $a=0.0419$ & 0.98 & 0.073 & 0.04 & 0.08 & 8 \\
\hline & $b=0.0192$ & & & & & \\
\hline \multirow[t]{2}{*}{ desethylatrazine } & $a=0.0097$ & 0.98 & 0.033 & 0.03 & 0.07 & 12 \\
\hline & $b=0.0099$ & & & & & \\
\hline \multirow[t]{2}{*}{ linuron } & $a=-0.0031$ & 0.92 & 0.012 & 0.07 & 0.15 & 11 \\
\hline & $b=0.0015$ & & & & & \\
\hline
\end{tabular}

(1): $Y$ : compound area measured on caracteristic ion/internal standard area $(\mathrm{m} / \mathrm{z}=208)$. $X$ : concentration $\mu \mathrm{g} / \mathrm{L}$.

(2): $R^{2}$ : correlation coefficient.

(3): SD: Standard Deviation for " $a$ ".

(4): LOD: detection limit $=a+\mathrm{SD} a \cdot\left(2 \sqrt{2} \cdot t_{(0.05 \cdot 3)}\right)$ (with $t=$ student test).

(5): LOQ: quantification limit $=a+\mathrm{SD} a \cdot 10$.

(6): \% RSD: Relative Standard Deviation.

Table III. Statistical results for ANOVA 1 and ANOVA 2 tests.

\begin{tabular}{|c|c|c|c|c|c|c|c|c|c|}
\hline \multirow[t]{2}{*}{ Compounds } & \multirow[t]{2}{*}{$V_{p e}$} & \multirow[t]{2}{*}{$V_{l o f}$} & \multirow[t]{2}{*}{$V_{\text {res }}$} & \multirow[t]{2}{*}{$V_{\text {reg }}$} & \multirow[t]{2}{*}{$V_{t o t}$} & \multicolumn{2}{|c|}{ ANOVA 1} & \multicolumn{2}{|c|}{ ANOVA 2} \\
\hline & & & & & & $f_{\text {exp }}$ & $f_{\text {theo }}$ & $f_{\text {exp }}$ & $f_{\text {theo }}$ \\
\hline diuron & $1.98 \mathrm{E}-04$ & $7.30 \mathrm{E}-05$ & $1.82 \mathrm{E}-04$ & 0.13 & $5.73 \mathrm{E}-03$ & 734 & 4.35 & 0.37 & 8.66 \\
\hline chlortoluron & $7.94 \mathrm{E}-04$ & $2.91 \mathrm{E}-03$ & $1.07 \mathrm{E}-03$ & 0.83 & $3.58 \mathrm{E}-02$ & 780 & 4.35 & 3.66 & 8.66 \\
\hline simazine & $1.16 \mathrm{E}-02$ & $3.87 \mathrm{E}-03$ & $1.06 \mathrm{E}-02$ & 2.78 & $1.26 \mathrm{E}-01$ & 263 & 4.35 & 0.33 & 8.66 \\
\hline atrazine & $3.13 \mathrm{E}-03$ & $1.34 \mathrm{E}-02$ & $4.47 \mathrm{E}-03$ & 5.29 & $2.25 \mathrm{E}-01$ & 1184 & 4.35 & 4.28 & 8.66 \\
\hline isoproturon & $1.78 \mathrm{E}-03$ & $8.57 \mathrm{E}-03$ & $2.67 \mathrm{E}-03$ & 6.09 & $2.56 \mathrm{E}-01$ & 2280 & 4.35 & 4.80 & 8.66 \\
\hline terbutylazine & $9.97 \mathrm{E}-02$ & $8.84 \mathrm{E}-03$ & $3.57 \mathrm{E}-02$ & 37.9 & 1.62 & 1062 & 4.35 & 0.22 & 8.66 \\
\hline desethylatrazine & $7.02 \mathrm{E}-03$ & $1.14 \mathrm{E}-02$ & $7.59 \mathrm{E}-03$ & 10.2 & $4.34 \mathrm{E}-01$ & 1349 & 4.35 & 1.62 & 8.66 \\
\hline linuron & $8.50 \mathrm{E}-04$ & $1.22-03$ & $8.98 \mathrm{E}-04$ & 0.23 & $1.04 \mathrm{E}-02$ & 255 & 4.35 & 1.44 & 8.66 \\
\hline
\end{tabular}




\section{Original articles}

\section{Conclusion}

The simultaneous determination of triazine and phenylureas sets some crucial chromatographic problems: poor resolution and large difference of sensitivity with classical detection between these 2 families. These problems can now be twisted by the coupling LVI/GC/ITD. The injection of a large volume of the organic extract permits to realised quantitative analyses on more characteristic ions than those obtained by the classical injection $(1 \mu \mathrm{L})$ and to reached the very selective ITD particularly for ureas. This selectivity presents two advantages. First, the identification of compounds is easier and the similarity coefficients between the reference spectra and the measured ones are more important than those evaluated by GC/ITD. Secondly, the reconstitution of chromatograms on characteristic ions increases the resolution and then permits to quantify 2 co-eluted compounds. In the case of ureas, the quantification on molecular ions minimises the risk of interferences which was present by GC/ITD analysis. more generally, quantification is easier owing to the presence of more ions in the trap. The method which couples large volume injection to GC/ITD combines specificity and sensibility, it is then the method of choice for the analyses of pesticides at trace levels and should be a good way to perform multi-residues analysis by gas chromatography. The next development of this study is to improved our method on real sample and particulary on surface sample.

\section{References}

1. The pesticides manual tenth edition; Tomlin, C. Ed., 1994.

2. Barceló, D. Chromatographia 1988, 25, 928.

3. Barceló, D. J. Chromatogr. 1993, 643, 117.

4. Benfenati, E.; Tremolade, P.; Chiappetta, L.; Frassanito, R.; Bassi, G.; Di Torro, N.; Fanneli, R.; Stella, G. Chemosphere 1990, 21, 1411.
5. Mattern, G. C.; Singer, G. M.; Louis, J.; Robson, M.; Rosen, J. D. J. Agric. Food Chem. 1990, 38, 402.

6. Kadokami, K.; Sato, K.; Hanada, Y.; Shinohara, R.; Koga, M.; Shiraishi, H. Anal. Sci. 1995, 11, 375.

7. Pereira, W.E.; Rostad, C.E.; Leiker, T.J. Anal. Chim. Acta 1990, 228, 69 .

8. Cairns, T.; Chiu, K. S.; Navarro, D.; Siegmunk, E. Rapid. Commun. Mass Spectrom. 1993, 7, 971.

9. Lopez-Avila, V.; Wesselman, R.; Edgell, K. J. Assoc. Off. Anal. Chem. 1990, 73, 276.

10. Lartigue, S.; Garrigue, P. Analusis 1993, 21, 157.

11. Triantafyllos, A.; Hela, D. G. J. Chromatogr. 1995, 707, 283.

12. National pesticides survey, method 1, U.S. EPA 1988, 1.

13. Karg J. Chromatogr. 1993, 634, 87.

14. Charrêteur, C.; Colin, R.; Morin, D.; Péron, J. J.; Madec, C. L. Analusis 1996, 24, 203.

79. Charrêteur, C.; Kerbaol, N.; Péron, J. J. Varian GC/MS Application Note 50.

1. Charrêteur; C.; Kerbaol, N.; Péron, J. J. Analusis 1996, 24, 336.

2. Van Zoonen, P.; Van Der Hoff, G. R. LC-GC Internat. 1997, April, 240.

3. Mol, H. G. J.; Janssen, H. G. M.; Cramers, C. A.; Vreuls, J. J.; Brinkman, U. A. Th. J. Chromatogr. A 1995, 703, 277.

4. Analytical Methods Committee, Analyst 1994, November, 119, 2363.

5. Staniewski, J.; Rijks, J. A. J. Chromatogr. 1992, 623, 105.

6. Mol, H. G. J.; Janssen, H. G.; Cramers, C. A.; Brinkman, U. A. Th. J. High Res. Chromatogr. 1995, 18, 124.

7. Grob, K.; Jennings, W. G.; Bertsch, W.; Sandra, P. Eds.; On column injection in Capillary Gas Chromatography, Hüthig Heidelberg, 1987.

8. Charrêteur, C.; Huet, J. M.; Péron, J. J.; Madec, C. L. Analusis 1997, 25, 211.

9. ECC drinking water guidelines, PO/779/ECC $\mathrm{N}^{\circ}$ L229/11-29, Brussels, 30 Août 1980.

10. Charrêteur, C.; Université de Bretagne Occidentale France, Thèse, 1997.

11. Karg, F. J. Chromatogr. 1993, 634, 87.

12. Norme AFNOR XP T90-210, Janvier 1996. 